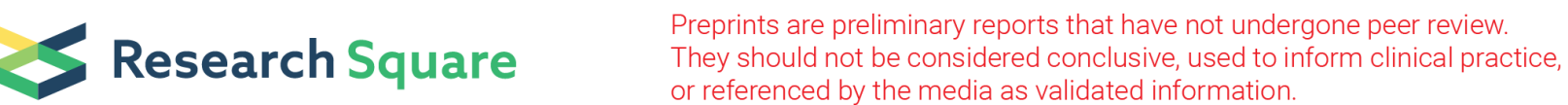

\section{Biosynthesis Zinc Oxide Nanoparticles Using Senna Occidentalis Leaf Extract and Evaluation of their Cytotoxic Effect on SW480 Colon Cancer Cell Line}

Nidhi chaudhary

MNNIT Allahabad: Motilal Nehru National Institute of Technology

Manish Pratap Singh

MNNIT Allahabad: Motilal Nehru National Institute of Technology

Preeti Sirohi

MNNIT Allahabad: Motilal Nehru National Institute of Technology

Shadma Afzal

MNNIT Allahabad: Motilal Nehru National Institute of Technology

Nand K. Singh ( $\nabla$ singhnand@gmail.com )

Motilal Nehru National Institute of Technology Allahabad https://orcid.org/0000-0001-5668-7081

Research Article

Keywords: Colorectal cancer, Cytotoxicity, Eco-friendly, Green synthesis, Nanotechnology.

Posted Date: January 11th, 2022

DOI: https://doi.org/10.21203/rs.3.rs-1215740/v1

License: (c) (i) This work is licensed under a Creative Commons Attribution 4.0 International License.

Read Full License 


\section{Abstract}

\section{Objective}

In the present study, we green synthesized ZnO NPs (zinc oxide nanoparticles) from Senna occidentalis leaf extract which were subsequently assessed for their cytotoxic and antioxidant activity on colon cancer SW480 cell line.

\section{Results}

Zinc oxide nanoparticles were characterized by using UV-Vis spectroscopy, X-ray diffractometer (XRD), Particle size analyzer (PSA), Fourier transform infrared spectroscopy (FTIR), Field emission scanning electron microscopy (FE-SEM), Energy-dispersive X-ray (EDS) and atomic force microscope (AFM) analysis. The PSA, XRD and AFM showed $20-50 \mathrm{~nm}$ size and nearly cuboidal and irregular shaped of the $\mathrm{ZnO}$ NPs. The synthesized $\mathrm{ZnO}$ nanoparticles were evaluated for their anticancer activity on human colon cancer cell line (SW480) by using MTT and neutral red uptake assay. The SW480 colon cancer cells were treated with various concentrations of ZnO NPs in the range of $20-100 \mu \mathrm{g} / \mathrm{ml}$ for $2 \mathrm{hrs}$. The result showed that ZnO NPs could reduce cell viability of SW480 cells up to $50 \%$ at the concentration of 100 $\mu \mathrm{g} / \mathrm{ml}$ and induce membrane leakage in a concentration dependent manner.

\section{Conclusion}

The anticancer activity of zinc oxide nanoparticles has showed that these can be used as effective anticancer agent against colon cancer cell lines (SW480).

\section{Introduction}

Colorectal cancer (CRC) is the third most frequently detected malignancy and the fourth major root of cancer-allied deaths in the world which is predicted to rise by sixty percent to more than 2 million newfangled cases and 1 million cancer deaths by 2030. CRC caused annual death are counted around thousands of people, accounting for $10 \%$ of cancer-allied mortality (Kuipers et al. 2016; Rampado et al. 2019). In 1950, CRC was limited, but now it has become a major cancer in Asia, Eastern Europe, India and South America. The prevalent reasons of CRC include western lifestyle, diet, overweight, lack of physical activity, alcohol drinking habit, smoking and especially the red meat consumption (Bisht and Rayamajhi 2016; Gnanavel et al. 2017).

An increased access to adequate medical care has significantly improved the diagnosis and medicinal treatment of diseases. These measures have had an effect on average life expectancy in most areas of the world. Over the previous few years, nanotechnology has arisen as a most promising technique for several biomedical applications (Priyadharshini et al. 2014; Kuppurangan et al. 2016; Selim et al. 2020). The small size property of NPs provides a high surface area to volume ratio, which allows increased drug efficiency, surface contact, solubility and reactivity and other broad ranges of application (Huang et al. 
2013; Namvar et al. 2016). Nowadays, the available nanomaterials such as metal NPs have been explored as a biomedical agent as well as new carriers for the transmission of therapeutic agents for the various type of diseases (Herlekar et al. 2014). Several natural resources have been used for the synthesis of nanoparticles such as plants, plant sources and microorganisms (bacteria, viruses and yeast) (Basak et al. 2018). Plants are the most favoured source for the synthesis of NPs, due to their promising lead to the large production of NPs with reliable stability and a variety of sizes and shapes. There are three approaches used for nanoparticle synthesis such as physical, chemical and biological (green synthesis) methods. In physical and chemical methods have some disadvantages such as low yield and uses of toxic chemicals (borohydride, citrate or other organic compounds) respectively. These methods are also not suitable for synthesis of desirable and well-defined size of nanoparticles. Whereas, biological (green synthesis) methods usages enzymatic reduction, which better regulate the size and shape of the NPs and easy, nontoxic, efficient and environmentally friendly, as comparison with other methods (Namvar et al. 2015). Several researches have revealed that the size of NPs is directly proportional to the toxicity they exhibit. Additionally, manipulation of size is important for supplying higher EPR (Enhanced Permeation and Retention) effect to enhance intra-tumour concentration of NPs (Singh et al. 2018). There are numerous targeting molecules and ligand that can be conjugated in the surface of NPs, which is a major aspect of NPs mediated drug delivery. Currently, NPs drug systems are becoming more sophisticated with the inclusion of targeting and multifunctional capabilities that could possibly overcome drug resistance and recover the treatment of metastatic diseases (Dey et al. 2018).

Zinc oxide nanoparticles are the important member of the metal oxide NPs family, which has ultraviolet rays absorbing property and pellucidity for visible light, producing these NPs excellent sunscreen agents (Rambabu et al. 2021). Other goods, such as their anticancer and antibacterial activities, have also been explored, which consequence of their ability to stimulate the production of reactive oxygen species (ROS) (Sharma et al. 2015; Bandeira et al. 2020). ZnO NPs have the great ability to generate oxidative stress in cancerous cells, which has shown the mechanism of cytotoxicity of ZnO NPs against cancer cells (Shamasi et al. 2021). This quality is due to the semiconductor nature of zinc oxide. Additionally, the generated ROS, leads to oxidative stress and finally cell death when the anti-oxidative activity of the cell is exceeded. The application of nanomaterials in the cancer treatment found that it can selectively kill cancer cells with astonishingly less toxicity against normal cells. Several studies have manifested that zinc oxide NPs exhibit selective cytotoxicity against cancer cells and kill cancerous cells by interpreting selective localization and cell cytotoxicity against them (Sivaraj et al. 2014). Hanley et al. (2008) recommended that ZnO NPs exhibit 28 to 35 times selective toxicity against cancer cells as compared to normal cells. Besides, the US Food and Drug Administration (FDA) have accepted bulk ZnO as a generally recognized as safe (GRAS) element, and the size of $\mathrm{ZnO}$ nanoparticles is less than $100 \mathrm{~nm}$ is determined to be relatively biocompatible and easily absorbed by the body, which making them effective choices for drug delivery (Akbarian et al. 2018).

Zinc oxide is normally considered as a material with low toxicity and show a strong property in enhancing the biomedical research (Jiang et al. 2018). $\mathrm{Zn}$ is an essential co-factor in several cellular mechanisms and play an essential role in managing cellular homeostasis as well as it plays an important role in 
protein synthesis, nucleic acid and metabolism. The most prominent property of ZnO NPs is eco-friendly and biodegradability (Saravanan et al. 2018). In addition, plant constituents, including carbohydrates, proteins and enzymes are used to formulate NPs that can easily make interaction with biomolecules. Plants contain secondary metabolites such as lignin, hemicellulose, pectin, flavonoids and antioxidant polyphenolic compounds which possess cytotoxic activity, leads towards the development of effective drugs (Singh et al. 2019). Few studies have been reported showing the cytotoxicity of ZnO NPs (Vidya et al. 2013), yet till now no study has been reported showing the anti-cancer potential of ZnO NPs on SW480 colon cancer cell line. Hence the aim of this study is to synthesize ZnO NPs using an eco-friendly route and then subsequent evaluation of the in vitro cytotoxic effect of the prepared ZnO NPs on SW480 colon cancer cell lines.

\section{Materials And Methods}

\section{Plant Materials}

The fresh leaves of Senna occidentalis were collected from the MNNIT campus (Allahabad) Prayagraj District of U.P., India. All aqueous solutions were prepared by using distilled water. Zinc acetate [Zn $\left.\left(\mathrm{O}_{2} \mathrm{CCH}_{3}\right)_{2}\left(\mathrm{H}_{2} \mathrm{O}\right)_{2}\right]$ and $\mathrm{NaOH}$ were obtained from Sigma Aldrich Chemicals Ltd. India. Double distilled water was also utilized in this experiment.

\section{Plant extract preparation}

$10 \mathrm{~g}$ of fresh and healthy leaves were cleaned with running water, sterilized with distilled water then cut into small pieces and soaked in a beaker containing $200 \mathrm{ml}$ distilled water The aqueous solution was heated at $60^{\circ} \mathrm{C}$ for $2 \mathrm{hrs}$. The Senna occidentalis leaf extract was left to cool at room temperature, filtered by Whatman filter paper Number 1 and the filtrate was kept at $4^{\circ} \mathrm{C}$ used for further experiments.

Biosynthesis of ZnO NPs

The $1 \mathrm{mM}$ of Zinc acetate $\left[\mathrm{Zn}\left(\mathrm{O}_{2} \mathrm{CCH}_{3}\right)_{2}\left(\mathrm{H}_{2} \mathrm{O}\right)_{2}\right]$ was dissolved in $50 \mathrm{ml}$ double distilled water and placed at magnetic stirrer for 20 min respectively. Then $25 \mathrm{ml}$ of sodium hydroxide solution was gradually added into zinc acetate solution and $25 \mathrm{ml}$ of Senna occidentalis plant leaf extract was dropwise added. After one hours of incubation, the colour of the reaction mixture was transformed. The reaction mixture was left in a magnetic stirrer for two hours, milky white color developed after the incubation that confirmed the biosynthesis of zinc oxide nanoparticles. The resulting precipitate was separated from the reaction mixture through centrifugation at $6000 \mathrm{rpm}, 60^{\circ} \mathrm{C}$ for 15 minutes and then pellet was accumulated, dried by hot air oven (working at $80^{\circ} \mathrm{C}, 2 \mathrm{hrs}$ ) and kept at $4{ }^{\circ} \mathrm{C}$ for further analysis.

Characterization of zinc oxide nanoparticles

The UV-Vis spectroscopy of the ZnO solution was recorded by double beam UV-Vis spectrophotometer. For the extracellular, optical density (OD) ranges measured from 200-800 nm. Based on the OD values, 
the peak was represented as an optimum NP synthesis. The shape and size of the NPs could also be predicted via UV-Vis spectroscopy (Gnanavel et al. 2017). The structural analysis of the biosynthesized ZnO NPs was done through a powder X-ray diffractometer (XRD) (Rigaku Smart Lab) technique. The crystalline phase was calculated by $2 \theta$ values obtained from $X$-ray diffractometer analysis using DebyeScherrer's equation. Thus, XRD technique is used for the determination of size, crystalline structure and purity of the NPs. Particle size analyzer (PSA) technique used for the determination of the size distribution profile of nano particles in the solution. Fourier transform infrared spectroscopy (FTIR) (PerkinElmer), used to identify the ZnO NPs associated biomolecules and the FTIR spectroscopy spectrum analysis was recorded in the range of $4000-400 \mathrm{~cm}^{-1}$ (Bajpai et al. 2016). Several vibration stretches were detected in the FTIR spectrum analysis to determine various functional groups associated with the ZnO NPs. The surface morphology of ZnO NPs was determined by Field emission scanning electron microscopy (FE-SEM) (Nova NanoSEM 450). Elemental compositions of the biosynthesized NPs were determined by Energy-dispersive X-ray spectroscopy (EDS) (Wang et al. 2016). The surface topological studies of the NPs were carried out by atomic force microscope (AFM). The AFM technique was carried out by drop coating the dispersion containing the particles onto a microscopic glass slide after required scanning and reaction time. The shape and size of the ZnO NPs were also determined through the AFM (Gupta and Gupta 2005; Satyavani et al. 2011).

\section{Cell cultures}

Human colon cancer cell lines SW480 were procured from the National Centre for Cell Science (NCCS) Pune, Maharashtra, DMEM medium supplemented with $2 \mathrm{mM}$ L-glutamine and $10 \%$ FBS with streptomycin $100 \mu \mathrm{g} / \mathrm{ml}$ and penicillin $100 \mathrm{U} / \mathrm{ml}$ (Sigma-Aldrich, USA). According to NCCS protocol, cell was cultured in $25 \mathrm{~cm}^{2}$ cell culture flasks at $37{ }^{\circ} \mathrm{C}$ in a $5 \% \mathrm{CO}_{2}$ humidified incubator. The cell cultures were regularly studied under an inverted microscope for viability and confluency.

\section{Cytotoxicity Assay}

The cytotoxicity or viability assays are significant for detecting the toxicity that shows the cellular effect of a toxic chemical and provides information on metabolic activities, survival and cell death (Chunyan and Valiyaveettil 2013). The concentration and time dependent research were done to find out the effect of zinc oxide nanoparticles on cell viability.

\section{MTT assay}

Human colon cell lines SW480 were seeded onto the 96 well cell culture plates at a density of 10,000 cells/ well and incubated for overnight at $37{ }^{\circ} \mathrm{C}$ in $5 \% \mathrm{CO}_{2}$ atmosphere. The cellular mechanism of reduction of MTT into formazan involves reaction with a mitochondrial enzyme (mitochondrial lactate dehydrogenase) for live/ viable cells. Dimethyl sulfoxide (DMSO) is a solubilizing buffer, which added for dissolution of MTT formazan crystal afterward, this crystal develops a purple color and act as a marker of the viable cells (Gurunathan et al. 2013). The color intensity is recorded in spectrophotometrically and it is proportional to the number of live cells. The colon cancer cells were plated with different 
concentrations of ZnO NPs (20,40,60, 80 and $100 \mu \mathrm{g} / \mathrm{ml})$. Untreated cells and $\mathrm{ZnO}$ nanoparticles controls were involved in each assay to compare with the complete cell viability assessments. All cultures were incubated at $37^{\circ} \mathrm{C}$ for $2 \mathrm{hrs}$ in a $\mathrm{CO}_{2}$ humidified incubator. After the incubation $\left(5 \% \mathrm{CO}_{2}\right.$ in a humid atmosphere, $\left.37^{\circ} \mathrm{C}\right), 100 \mu \mathrm{l}$ of MTT $(0.5 \mathrm{mg} / \mathrm{ml}$ dissolved in phosphate buffer saline) was added to each well, and the culture plate was incubated for further $4 \mathrm{hrs}$ at $37^{\circ} \mathrm{C}$ followed by formation of purple color crystals. The resulting formazan was solubilized by addition of $100 \mu$ l Dimethyl sulfoxide (DMSO) with gentle shaking at $37^{\circ} \mathrm{C}$, and the absorbance (OD) was recorded at $570 \mathrm{~nm}$ with an ELISA plate reader. The cell viability (\%) was calculated by the following formula:

Cell viability $(\%)=$ OD of experimental samples $/ O D$ value of experimental controls $\times 100$

Neutral red uptake assay

The principle of the neutral red assay (NRU) is depending on the recognition of live/ viable cells through the uptake of dye. Viable cells have ability to uptake neutral red through active transport, incorporate and bind the dye into their lysosomes whereas non-viable or dead cells are unable to absorb this chromophore. Subsequently washing the cells, the viable cells can discharge the incorporated dye during acidified extracted conditions. The quantity of releasing dye can be used to estimate the total no. of viable cells. The NRU assay to determine the cytotoxic effect of the zinc oxide NPs at different concentrations. The SW480 cells were plated in 96-well culture plates with different concentrations of zinc oxide NPs $(20,40,60,80$ and $100 \mu \mathrm{g} / \mathrm{ml})$. All cell cultures were incubated at $37^{\circ} \mathrm{C}$ for 2 hours in a $\mathrm{CO}_{2}$ humidified incubator. Neutral red dye was prepared by diluting the stock $(4 \mathrm{mg} / \mathrm{ml})$ concentration by adding PBS in 1:100 ratio. After $2 \mathrm{hrs}$ of incubation ( $37^{\circ} \mathrm{C}, 5 \% \mathrm{CO}_{2}$ in a humid condition), $100 \mu \mathrm{l}$ of neutral red was added to well and the culture plate was incubated for an extra 4 hours at $37^{\circ} \mathrm{C}$. After the $4 \mathrm{hrs}$ neutral red dye incubation, extra neutral red dye is decanted and $150 \mu \mathrm{l}$ solvent is added to each well. The solvent extracts the neutral red contained within the colon cancer cells. Gently stir in a shaker to completely extract the neutral red dye and absorbance was taken at $540 \mathrm{~nm}$ with an ELISA plate reader (Uzar et al. 2015).

\section{Results And Discussion}

Biosynthesis and characterization of ZnO Nanoparticles

ZnO NPs have attracted great attention due to their optical abilities. Visual color change is the initial test for NP synthesis (Afzal et al. 2019; Alrubaie and Kadhim 2019). When the plant leaf extract was added in $\mathrm{ZnO}$ solution, the white solution converted into milky white color, which is the strong indication of the synthesis of ZnO NPs in the reaction solution. The color change shows that the Senna occidentalis leaf extract could be act as a stabilizing and reducing agent for ZnO NPs synthesis.

UV-Vis spectroscopy analysis 
UV-Vis spectroscopy is a principal technique for the characterization of ZnO NPs. The optical properties of a metal NPs depends primarily on its surface plasmon resonance, which refers to the collective free electron oscillation within the metal NPs (Singh et al. 2016). Conducting free electrons begin oscillating at a particular wavelength range due to SPR effect. The UV-Vis absorption spectra of the ZnO nanoparticles were measured in the ranging from 358 to $375 \mathrm{~nm}$, (Fig. 1) shows, the UV-Vis spectra of freshly synthesized zinc oxide NPs. The absorption peak found at $390 \mathrm{~nm}$ clearly indicate the formation of zinc oxide NPs. This result is similar with other reported results (Elumalai and Velmurugan 2015).

X-ray diffraction analysis

The crystallinity and structural information of ZnO NPs prepared using Senna occidentalis fresh leaf extract is studied by X-ray diffraction pattern as shown in (Fig. 2). The intense, strong and sharp peaks of ZnO NPs clearly showed that the resulting products are highly crystalline. The size of the NPs was calculated by the Debye-Scherrer equation. The Bragg reflections were observed at $2 \theta=31.86^{\circ}, 34.72^{\circ}$, $36.57^{\circ}, 47.66^{\circ}, 56.89^{\circ}, 61.74^{\circ}, 68.69^{\circ}, 69.60^{\circ}$ associated with the lattice planes of (100), (002), (101), (102), (110), (103), (112), (201) for the fcc crystal structure of zinc oxide NPs. Similar results have also been reported (Moos et al. 2010). The JCPDS was work as a reference to assign the lattice planes on the basis of peaks obtained. The Average crystalline size of the biosynthesize ZnO NPs was estimated to be $37 \mathrm{~nm}$.

$D=K \lambda / \beta \cos \theta$

where, D- nanoparticle size in nm, $\lambda$-X-ray wavelength, $\beta$ - FWHM, $\theta$ - Bragg's angle of reflection.

Particle size analyzer analysis

The hydrodynamic size distribution of biosynthesized $\mathrm{ZnO}$ nanoparticles was determined using PSA and the size was found to be $46.3 \mathrm{~nm}$. PSA results showed the size distribution of bio-synthesized ZnO NPs ranged from 15 to $100 \mathrm{~nm}$; the maximum proportion of the synthesized NPs was detected to be in the range of 30 to $80 \mathrm{~nm}$ (Fig. 3). Similar results have also been reported (Santhoshkumar et al. 2017).

Fourier Transforms Infrared Spectroscopy analysis

These figures (Fig. 4A, B) show the functional groups in Senna occidentalis leaf extract and determine their role in ZnO NPs synthesis. The FTIR spectrum of the ZnO NPs prepared using Senna occidentalis fresh leaf extract with absorption peaks situated between $4000 \mathrm{~cm}^{-1}$ and $400 \mathrm{~cm}^{-1}$. Bands detected at $3425.21 \mathrm{~cm}^{-1}$ allocated to $0-\mathrm{H}$ phenol group stretching. The bands identified at $1636.3 \mathrm{~cm}^{-1}$ could be allocated to $\mathrm{C}=0$ ketone group stretching. The bands detected at $1561.78 \mathrm{~cm}^{-1}$ assigned to the stretching amide group vibrations. The bands detected at $1411.32-1021.41 \mathrm{~cm}^{-1}$ could be allocated to the $\mathrm{C}-\mathrm{C}$ stretches of aromatic rings. The bands $830.29 \mathrm{~cm}^{-1}$ can be allocated to amide group vibrations. The $\mathrm{C}-\mathrm{H}$ stretching alkanes could be allocated to the bands at $(645.80,568.75,422.30) \mathrm{cm}^{-1}$. The bands shift to significantly lesser frequency give the sign for the depositions of these compounds in the zinc oxide 
nanoparticle synthesis, such as $3321.57 \mathrm{~cm}^{-1}$ reduced to $3425.21 \mathrm{~cm}^{-1}, 1380.83 \mathrm{~cm}^{-1}$ to $1411.32 \mathrm{~cm}^{-1}$, $1086.21 \mathrm{~cm}^{-1}$ to $1021.41 \mathrm{~cm}^{-1}$ and $880.39 \mathrm{~cm}^{-1}$ to $830.29 \mathrm{~cm}^{-1}$. This is similar to the ZnO NPs and phytochemicals on the surface (Arora 2015; Khyade et al. 2015). Additionally, a substantial band acted at $568.75 \mathrm{~cm}^{-1}$, owned by zinc oxide vibrational stretching, which more detected on zinc oxide nanoparticle formation. Thus, from the FTIR spectrum, it can be observed that Senna occidentalis sample is rich in polyphenols, polysaccharide, amino acid, carboxylic acid and proteins. These biomolecules play a major role in the defence of cells against the harmful effect of ROS by neutralizing free radical production. Plant polyphenols have a greater antioxidant property and phytochemicals acted as reducing, capping, and stabilizing agent that evident from the FTIR spectrum of the synthesized ZnO NPs (Siddiquah et al. 2018).

Field emission scanning electron microscopy and Energy-dispersive X-ray spectroscopy analysis

The crystalline shape, surface morphology and size of the synthesized ZnO NPs are investigated through using FE-SEM as shown in (Fig. 5A, B). The images of individual $\mathrm{ZnO}$ nanoparticles show a number of aggregates and the particle shape was nearly cuboidal and irregular (Balraj et al. 2017). Synthesis of ZnO NPs from the fresh leaf extract of Senna occidentalis and the size of NPs was found to be within 20-50 $\mathrm{nm}$. The FE-SEM analysis was also used to assess the structure of the products that produced. The synthesized ZnO NPs was further confirmed by EDS as shown in (Fig. 6). The elemental compositional analysis attained, could accurately quantify the $Z n$ and $O$ contents. The EDS spectrum exhibited $Z n$ and $\mathrm{O}$ absorption peaks and showed the presence of $\mathrm{ZnO}$ phase without any impurity. This analysis, were $59 \%$ zinc and $40 \%$ oxides, which shows the elemental composition of zinc oxide NPs. Almost similar peaks were shows with Euphorbia prostrata fresh leaves extract in ZnO NPs synthesis (Elkader 2012; Chung et al. 2015).

Atomic force microscopy (AFM) Analysis

The AFM technique is performed to study the size and topological appearance, giving a 3-dimensional profile in nanoscale (Aysa and Salman 2016). The nanoparticles size shows a significant role in the process of cell membrane diffusion. The smaller the nanoparticle size the larger the surface area which enhances the penetration ability of NPs with effective cytotoxicity and adsorption of biomolecules on ZnO NPs (Ezhilarasi et al. 2016). In the present analysis (Fig. 7), the NPs size was found about $37.3 \mathrm{~nm}$ based on AFM and the result were in accordance with XRD and PSA studies. The result also exhibits the polycrystalline nature of ZnO NPs.

Cytotoxicity analysis of zinc oxide NPs on colon cancer cell lines

Metabolically active cells were converted by MTT reagent into a purple formazan with maximum absorbance at $570 \mathrm{~nm}$. Only the viable cells are able to convert MTT into formazan crystal. The in vitro cytotoxic effects of biosynthesized zinc oxide NPs at concentrations 20,40,60,80 and $100 \mu \mathrm{g} / \mathrm{ml}$ was assessed with the MTT assay (Fig. 8A). Dimethyl sulfoxide was also used as a control for the activity (Gurunathan et al. 2013; Palanisamy et al. 2017). The results obtained from MTT assay showed that 
colon cancer cells after the treatment with $100 \mu \mathrm{g} / \mathrm{ml}$ of ZnO NPs $50 \%$ of cells remained viable. The antioxidant activity and cytotoxicity of zinc oxide NPs was enhanced by increasing the concentration of nanoparticles.

The neutral red uptake dye is also a cytotoxicity test assay that used to analyse cell viability. In vitro cytotoxic effects of biosynthesized ZnO nanoparticles at the concentrations 20,40,60, 80 and $100 \mu \mathrm{g} / \mathrm{ml}$ was evaluated using the Neutral red assay (Fig. 8B). The antioxidant activity and cytotoxicity of zinc oxide NPs was enhanced by increasing the concentration of nanoparticles. Thus, the administered nanoparticles concentration plays a significant role in the anti-cancerous property. Nanoparticles may enter the cell membrane via ion channels located on cell membranes and interact with intracellular proteins and nitrogenous bases of DNA.

Similar results were reported in a study that zinc oxide nanoparticles showed strong cytotoxicity against (MCF-7) breast cancer cell lines at the concentration of $50 \mu \mathrm{g} / \mathrm{ml}$ (Boroumand Moghaddam et al. 2017). The cell viability of breast cancer cell lines decreases with an enhances in zinc oxide nanoparticles concentration. In another study, HA/ZnO nanocomposite prevent the proliferation of cancer cell lines in a time and concentration dependent manner (Malaikozhundan et al. 2017). The zinc oxide was not toxic to normal MRC-5 human lung cells.

According to Li et al. (2017), $1000 \mu \mathrm{g} / \mathrm{ml} \mathrm{ZnO}$ NPs showed cytotoxicity against cervical cancer lines, where $98.9 \%$ of cancer cells died. ZnO NPs indicate the effective preferential cell cytotoxicity the concentration ranging from 25 to $100 \mu \mathrm{g} / \mathrm{ml}$ with improved preferential cytotoxicity presented by the Triton X-100 modification (Namvar et al. 2014). In a study, the cytotoxicity effect of ZnO NPs showed their capability for tumour reduction which suggests the biosynthesized zinc oxide nanoparticles can be used as novel anticancer agents for the liver cancer treatment (Chung et al. 2015).

\section{Conclusion}

Green synthesis of ZnO NPs used in the current study is found to be cost-effective, environment-friendly, simple and less use of chemicals in comparison to chemical and physical method. In this experiment, the ZnO NPs were successfully synthesized using the Senna occidentalis leaf extract and characterized by UV-vis spectroscopy, XRD, PSA, FTIR, FE-SEM, EDS and AFM pattern. The XRD technique showed the crystalline nature of the ZnO NPs. The phytoconstituents present in the plant leaf extract were involved in the biosynthesis of ZnO NPs by generating oxidation-reduction (redox) reaction. The functional groups present in NPs synthesis were mainly amide and alkanes. The FE-SEM analysis confirmed that the synthesized ZnO NPs were nearly cuboidal and irregular in shape with size ranging from 20-50 nm. Moreover, the EDS examination confirmed the purity of synthesized NPs with evidenced occurrence of zinc and oxide ions in the NPs. The anticancer activity of zinc oxide nanoparticles has showed that these can be used as effective anti-cancer agent against colon cancer cell lines (SW480). Our study requires more in vivo experiments such as immunofluorescence analysis, cell cycle assay, caspase assay and 
DNA fragmentation etc. to better understand zinc oxide nanoparticles cytotoxicity and future biomedical applications.

\section{Abbreviations}

CRC, colorectal cancer; ZnO NPs, zinc oxide nanoparticles; XRD, X-ray diffractometer; PSA, Particle size analyzer; FTIR, Fourier transform infrared spectroscopy; FE-SEM, Field emission scanning electron microscopy; EDS, Energy-dispersive X-ray; AFM, atomic force microscope; MTT, (3-(4,5-Dimethylthiazol-2yl)-2,5-Diphenyltetrazolium Bromide); EPR, Enhanced Permeation and Retention; ROS, reactive oxygen species; FDA, Food and Drug Administration; GRAS, generally recognized as safe; OD, optical density; DMEM, Dulbecco's Modified Eagle Medium; FBS, Fetal bovine serum; DMSO, Dimethyl sulfoxide; ELISA, enzyme-linked immunosorbent assay; NRU, neutral red assay.

\section{Declarations}

Author contributions Devised and designed the experiment: NKS and NC. Performed the experiments: NC, SA, PS, and MPS. Analysed the data: NC, SA, PS and AKY. Wrote the paper: NC and PS. All authors provided critical feedback and helped shape the research, analysis and manuscript.

Conflicts of interest The authors state that there are no conflicts of interest.

Funding sources This research did not receive any specific grant from funding agencies in the public, commercial, or not-for-profit sectors.

Acknowledgments The authors are grateful to the Director of MNNIT Allahabad, Prayagraj-211004, UP, India for providing research laboratory for performing this experiment. The authors acknowledge CIR, MNNIT Allahabad for providing XRD, PSA and AFM facilities; MRC, MNIT Jaipur for providing FTIR, DHSGSU for providing FE-SEM and EDS facilities. Author is thankful to the MHRD, Govt. of India, New Delhi, India for providing support during this tenure.

\section{References}

1. R. Rampado, S. Crotti, P. Caliceti, S. Pucciarelli, M. Agostini, Nanovectors design for theranostic applications in colorectal cancer, J. Oncol. (2019).

2. E.J. Kuipers, W.M. Grady, D. Lieberman, T. Seufferlein, J.J. Sung, P.G. Boelens, C.J.H. van de Velde, T. Watanabe, Colorectal cancer (2016). https://doi:10.1038/nrdp.2015.65.

3. V. Gnanavel, V. Palanichamy, S.M. Roopan, Biosynthesis and characterization of copper oxide nanoparticles and its anticancer activity on human colon cancer cell lines (HCT-116), J. Photochem. Photobiol. B, Biol. 171 (2017) 133-138.

4. G. Bisht, S. Rayamajhi, ZnO nanoparticles: a promising anticancer agent, Nanobiomedicine 3 (2016) 3-9. 
5. Priyadharshini, R.I., G. Prasannaraj, N. Geetha, P. Venkatachalam, Microwave-mediated extracellular synthesis of metallic silver and zinc oxide nanoparticles using macro-algae (Gracilaria edulis) extracts and its anticancer activity against human PC3 cell lines, Appl. Biochem. Biotechnol. 174 (2014) 2777-2790.

6. G. Kuppurangan, B. Karuppasamy, K. Nagarajan, R.K. Sekar, N. Viswaprakash, T. Ramasamy, Biogenic synthesis and spectroscopic characterization of silver nanoparticles using leaf extract of Indoneesiella echioides: in vitro assessment on antioxidant, antimicrobial and cytotoxicity potential, Appl. Nanosci. 6 (2016) 973-982.

7. G. Huang, H. Chen, Y. Dong, X. Luo, H. Yu, Z. Moore, E.A. Bey, D.A. Boothman, J. Gao, Superparamagnetic iron oxide nanoparticles: amplifying ROS stress to improve anticancer drug efficacy, Theranostics 3 (2013) 116.

8. F. Namvar, S. Azizi, H.S. Rahman, R. Mohamad, A. Rasedee, M. Soltani, R.A. Rahim, Green synthesis, characterization, and anticancer activity of hyaluronan/zinc oxide nanocomposite, Onco Targets Ther. 9 (2016) 4549.

9. M. Herlekar, S. Barve, R. Kumar, Plant-mediated green synthesis of iron nanoparticles, J. Nanopart. (2014). http://dx.doi.org/10.1155/2014/140614.

10. P. Basak, R. Majumder, A. Jasu, S. Paul, S. Biswas, Potential therapeutic activity of bio-synthesized silver nanoparticles as anticancer and antimicrobial agent, In IOP Conference Series: Mater. Sci. Eng., IOP Publishing, v410, 1 (2018) pp. 012020. https://doi:10.1088/1757-899X/410/1/012020.

11. F. Namvar, H.S. Rahman, R. Mohamad, S. Azizi, P.M. Tahir, M.S. Chartrand, S.K. Yeap, Cytotoxic effects of biosynthesized zinc oxide nanoparticles on murine cell lines, Evid. Based Complementary Altern. Med. (2015).

12. A. Singh, N.B. Singh, S. Afzal, T. Singh, I. Hussain, Zinc oxide nanoparticles: a review of their biological synthesis, antimicrobial activity, uptake, translocation and biotransformation in plants, J. Mater. Sci. 53 (2018) 185-201.

13. A. Dey, A. Yogamoorthi, S. Sundarapandian, Green synthesis of gold nanoparticles and evaluation of its cytotoxic property against colon cancer cell line, RJLBPCS J. 4 (2018) 1-17.

14. H. Sharma, P.K. Mishra, S. Talegaonkar, B. Vaidya, Metal nanoparticles: a theranostic nanotool against cancer, Drug Discov. Today 20 (2015) 1143-1151.

15. R. Sivaraj, P. Rahman, P. Rajiv, R. Venckatesh, Biogenic zinc oxide nanoparticles synthesis using Tabernaemontana divaricate leaf extract and its anticancer activity against MCF-7 breast cancer cell Lines, AABES (2014). http://dx.doi.org/10.15242/IICBE.C1014032.

16. C. Hanley, J. Layne, A. Punnoose, K.A. Reddy, I. Coombs, A. Coombs, K. Feris, D. Wingett, Preferential killing of cancer cells and activated human T cells using ZnO nanoparticles, Nanotechnology 19 (2008) 295103.

17. M. Akbarian, S. Mahjoub, S.M. Elahi, E. Zabihi, H. Tashakkorian, Urtica dioica L. extracts as a green catalyst for the biosynthesis of zinc oxide nanoparticles: characterization and cytotoxic effects on fibroblast and MCF-7 cell lines, New J. Chem. 42 (2018) 5822-5833. 
18. J. Jiang, J. Pi, J. Cai, The advancing of zinc oxide nanoparticles for biomedical applications. Bioinorg. Chem. Appl. (2018).

19. M. Saravanan, V. Gopinath, M.K. Chaurasia, A. Syed, F. Ameen, N. Purushothaman, Green synthesis of anisotropic zinc oxide nanoparticles with antibacterial and cytofriendly properties, Microb. Pathog. 115 (2018) 57-63.

20. A. Singh, I. Hussain, N.B. Singh, H. Singh, Uptake, translocation and impact of green synthesized nanoceria on growth and antioxidant enzymes activity of Solanum lycopersicum L., Ecotoxicol. Environ. Saf. 182 (2019) 109410.

21. C. Vidya, S. Hiremath, M.N. Chandraprabha, M.L. Antonyraj, I.V. Gopal, A. Jain, K. Bansal, Green synthesis of ZnO nanoparticles by Calotropis gigantea, Int. J. Curr. Eng. Technol. 1 (2013) 118-120.

22. V. Gnanavel, V. Palanichamy, S.M. Roopan, Biosynthesis and characterization of copper oxide nanoparticles and its anticancer activity on human colon cancer cell lines (HCT-116), Photochem. Photobiol. B, Biol. 171 (2017) 133-138.

23. S.K. Bajpai, M. Jadaun, S. Tiwari, Synthesis, characterization and antimicrobial applications of zinc oxide nanoparticles loaded gum acacia/poly (SA) hydrogels, Carbohydr. Polym. 153 (2016) 60-65.

24. Y. Wang, H. Zhang, Y. Zhu, Z. Dai, H. Bao, Y. Wei, W. Cai, Au-NP-decorated crystalline FeO Cl nanosheet: facile synthesis by laser ablation in liquid and its exclusive gas sensing response to $\mathrm{HCl}$ at room temperature, Adv. Mater. Interfaces 3 (2016) 1500801.

25. K. Satyavani, T. Ramanathan, S. Gurudeeban, Green synthesis of silver nanoparticles by using stem derived callus extract of bitter apple (Citrullus colocynthis), Dig. J. Nanomater. Biostruct. 6 (2011) 1019-1024.

26. A.K. Gupta, M. Gupta, Cytotoxicity suppression and cellular uptake enhancement of surface modified magnetic nanoparticles, Biomaterials 26 (2005) 1565-1573.

27. W. Chunyan, S. Valiyaveettil, Correlation of biocapping agents with cytotoxic effects of silver nanoparticles on human tumor cells, RSC Adv. 3 (2013) 14329-14338.

28. P. Priya Tharishini, N.C. Saraswathy, K.H. Smila, D. Yuvaraj, M. Chandran, P. Vivek, Green synthesis of gold nano particles from Cassia auriculata leaf aqueous extract and its cytotoxicity effect on in vitro cell line, Int. J. Chemtech Res. 6 (2014) 4241-4250.

29. N.K. Uzar, M. Abudayyak, N. Akcay, G. Algun, G. Özhan, Zinc oxide nanoparticles induced cyto-and genotoxicity in kidney epithelial cells, Toxicol. Mech. Methods 25 (2015) 334-339.

30. S. Afzal, P. Sirohi, A.K. Yadav, M.P. Singh, A. Kumar, N.K. Singh, A comparative screening of abiotic stress tolerance in early flowering rice mutants, J. Biotechnol. 302 (2019) 112-122.

31. E.A.A.A. Alrubaie, R.E. Kadhim, Synthesis of $\mathrm{ZnO}$ nanoparticles from olive plant extract, Plant Arch. 19 (2019) 339-344.

32. A. Singh, N.B. Singh, I. Hussain, H. Singh, V. Yadav, S.C. Singh, Green synthesis of nano zinc oxide and evaluation of its impact on germination and metabolic activity of Solanum lycopersicum, J. Biotechnol. 233 (2016) 84-94. 
33. K. Elumalai, S. Velmurugan, Green synthesis, characterization and antimicrobial activities of zinc oxide nanoparticles from the leaf extract of Azadirachta indica (L.), Appl. Surf. Sci. 345 (2015) 329336.

34. P.J. Moos, K. Chung, D. Woessner, M. Honeggar, N.S. Cutler, J.M. Veranth, ZnO particulate matter requires cell contact for toxicity in human colon cancer cells, Chem. Res. Toxicol. 23 (2010) 733-739.

35. J. Santhoshkumar, S.V. Kumar, S. Rajeshkumar, Synthesis of zinc oxide nanoparticles using plant leaf extract against urinary tract infection pathogen, Resource-Efficient Technologies 3 (2017) 459465.

36. K. Arora, Comparative account of allelopathic potential of different parts of Cassia occidentalis and its correlation with bio-molecular profile through FTIR, J. Chem. Pharm. Res. 7 (2015) 91-95.

37. M.S. Khyade, S.P. Kamble, A.R. Kurhe, A.D. Padwal, Comparative fourier transform infrared spectroscopic analysis and free radical quenching properties of three cassia species, Asian $\mathrm{J}$. Pharm. Clin. Res. 8 (2015) 119-125.

38. A. Siddiquah, S.S. Hashmi, S. Mushtaq, S. Renouard, J.P. Blondeau, R. Abbasi, C. Hano, B.H. Abbasi, Exploiting in vitro potential and characterization of surface modified Zinc oxide nanoparticles of Isodon rugosus extract: their clinical potential towards HepG2 cell line and human pathogenic bacteria, EXCLI J. 17 (2018) 671.

39. B. Balraj, N. Senthilkumar, C. Siva, R. Krithikadevi, A. Julie, I.V. Potheher, M. Arulmozhi, Synthesis and characterization of zinc oxide nanoparticles using marine Streptomyces sp. with its investigations on anticancer and antibacterial activity, Res. Chem. Intermed. 43 (2017) 2367-2376.

40. O. Abd Elkader, Preparation and characterization of nanostructured zinc oxide thin films, In AIP Conference Proceedings, American Institute of Physics, v1482,1 (2012) pp. 539542. https://doi:10.1063/1.4757530.

41. I.M. Chung, A.A. Rahuman, S. Marimuthu, A.V. Kirthi, K. Anbarasan, G. Rajakumar, An investigation of the cytotoxicity and caspase-mediated apoptotic effect of green synthesized zinc oxide nanoparticles using Eclipta prostrata on human liver carcinoma cells, Nanomaterials 5 (2015) 13171330.

42. N.H. Aysa, H.D. Salman, Antibacterial activity of modified zinc oxide nanoparticles against Pseudomonas aeruginosa isolates of burn infections, World Sci. News (2016) 1-14.

43. A.A. Ezhilarasi, J.J. Vijaya, K. Kaviyarasu, M. Maaza, A. Ayeshamariam, L.J. Kennedy, Green synthesis of NiO nanoparticles using Moringa oleifera extract and their biomedical applications: cytotoxicity effect of nanoparticles against HT-29 cancer cells, J. Photochem. Photobiol. B, Biol. 164 (2016) 352-360.

44. S. Gurunathan, J. Raman, S.N.A. Malek, P.A. John, S. Vikineswary, Green synthesis of silver nanoparticles using Ganoderma neo-japonicum Imazeki: a potential cytotoxic agent against breast cancer cells, Int. J. Nanomedicine 8 (2013) 4399.

45. S. Palanisamy, P. Rajasekar, G. Vijayaprasath, G. Ravi, R. Manikandan, N.M. Prabhu, A green route to synthesis silver nanoparticles using Sargassum polycystum and its antioxidant and cytotoxic 
effects: an in vitro analysis, Mater. Lett. 189 (2017) 196-200.

46. A. Boroumand Moghaddam, M. Moniri, S. Azizi, R. Abdul Rahim, A. Bin Ariff, M. Navaderi, R. Mohamad, Eco-friendly formulated zinc oxide nanoparticles: induction of cell cycle arrest and apoptosis in the MCF-7 cancer cell line, Genes 8 (2017) 281.

47. B. Malaikozhundan, B. Vaseeharan, S. Vijayakumar, K. Pandiselvi, M.A.R. Kalanjiam, K. Murugan, G. Benelli, Biological therapeutics of Pongamia pinnata coated zinc oxide nanoparticles against clinically important pathogenic bacteria, fungi and MCF-7 breast cancer cells, Microb. Pathog. 104 (2017) 268-2.

48. F. Namvar, H.S. Rahman, R. Mohamad, J. Baharara, M. Mahdavi, E. Amini, M.S. Chartrand, S.K. Yeap, Cytotoxic effect of magnetic iron oxide nanoparticles synthesized via seaweed aqueous extract, Int. J. Nanomedicine 9 (2014) 2479.

49. C.Y. Li, Z.C. Zhang, J.Y. Mao, L.F. Shi, Y. Zheng, J.L. Quan, Preparation of Tradescantia pallidamediated zinc oxide nanoparticles and their activity against cervical cancer cell lines, Trop. J. Pharm. Res. 16 (2017) 494-500.

50. Bandeira, M., Giovanela, M., Roesch-Ely, M., Devine, D.M. and da Silva Crespo, J., 2020. Green synthesis of zinc oxide nanoparticles: A review of the synthesis methodology and mechanism of formation. Sustainable Chemistry and Pharmacy, 15, p.100223.

51. Selim, Y.A., Azb, M.A., Ragab, I. and Abd El-Azim, M.H., 2020. Green synthesis of zinc oxide nanoparticles using aqueous extract of Deverra tortuosa and their cytotoxic activities. Scientific reports, 10(1), pp.1-9.

52. Rambabu, K., Bharath, G., Banat, F. and Show, P.L., 2021. Green synthesis of zinc oxide nanoparticles using Phoenix dactylifera waste as bioreductant for effective dye degradation and antibacterial performance in wastewater treatment. Journal of hazardous materials, 402, p.123560.

53. Shamasi, Z., Es-haghi, A., Taghavizadeh Yazdi, M.E., Amiri, M.S. and Homayouni-Tabrizi, M., 2021. Role of Rubia tinctorum in the synthesis of zinc oxide nanoparticles and apoptosis induction in breast cancer cell line. Nanomedicine Journal, 8(1), pp.65-72.

\section{Figures}




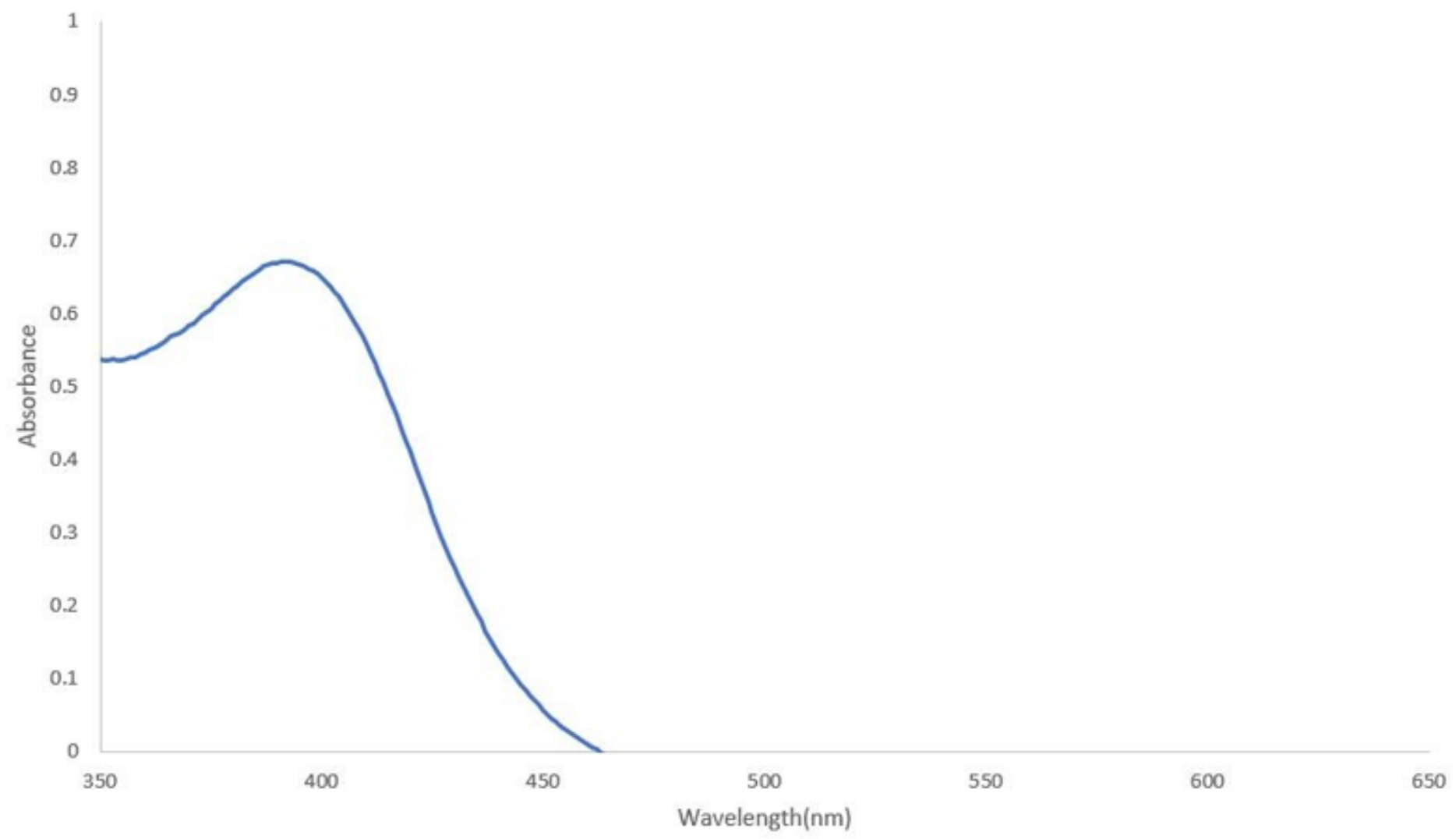

Figure 1

UV-Vis spectrum of the synthesized ZnO NPs. 


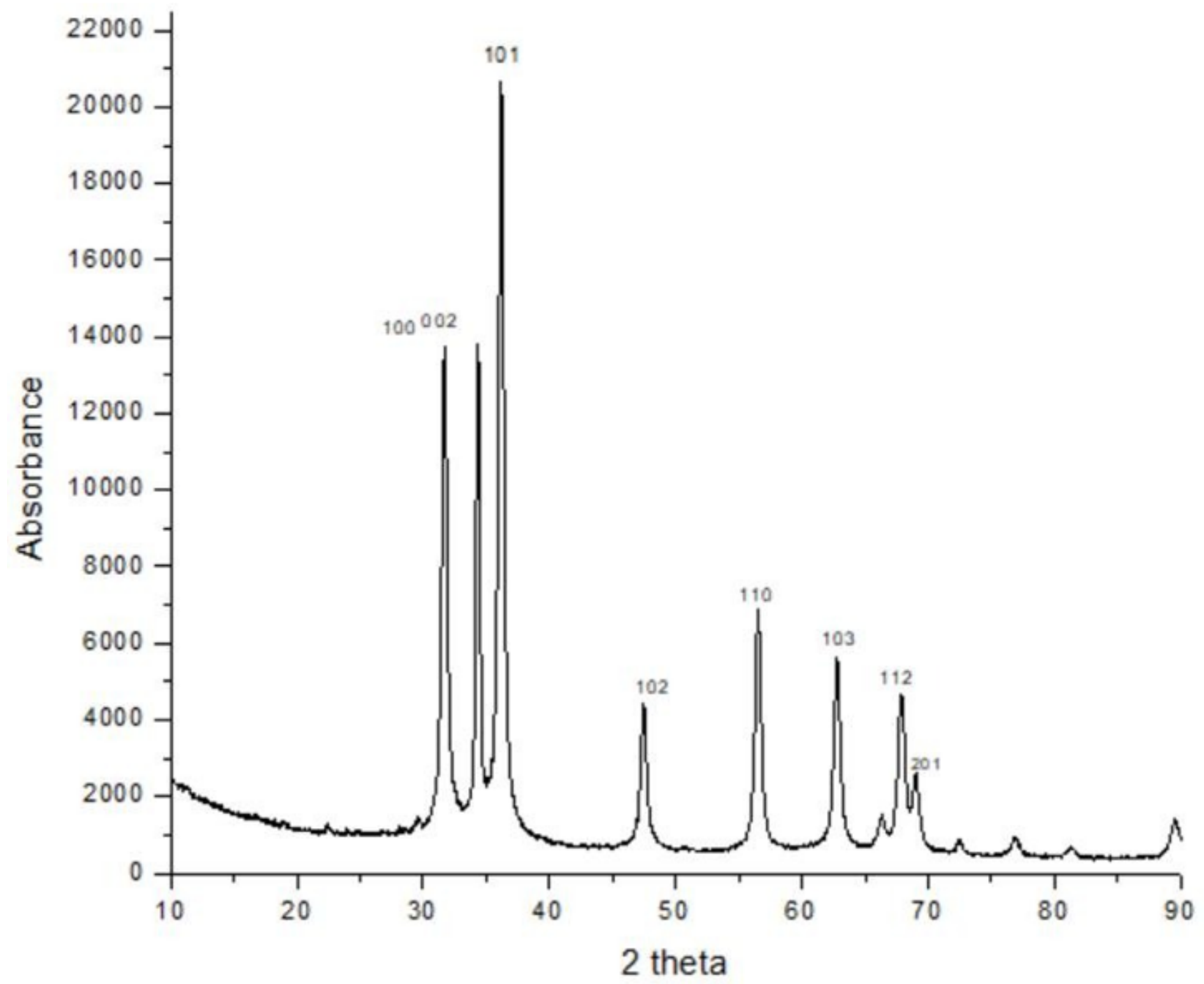

Figure 2

XRD pattern of synthesized ZnO NPs. 


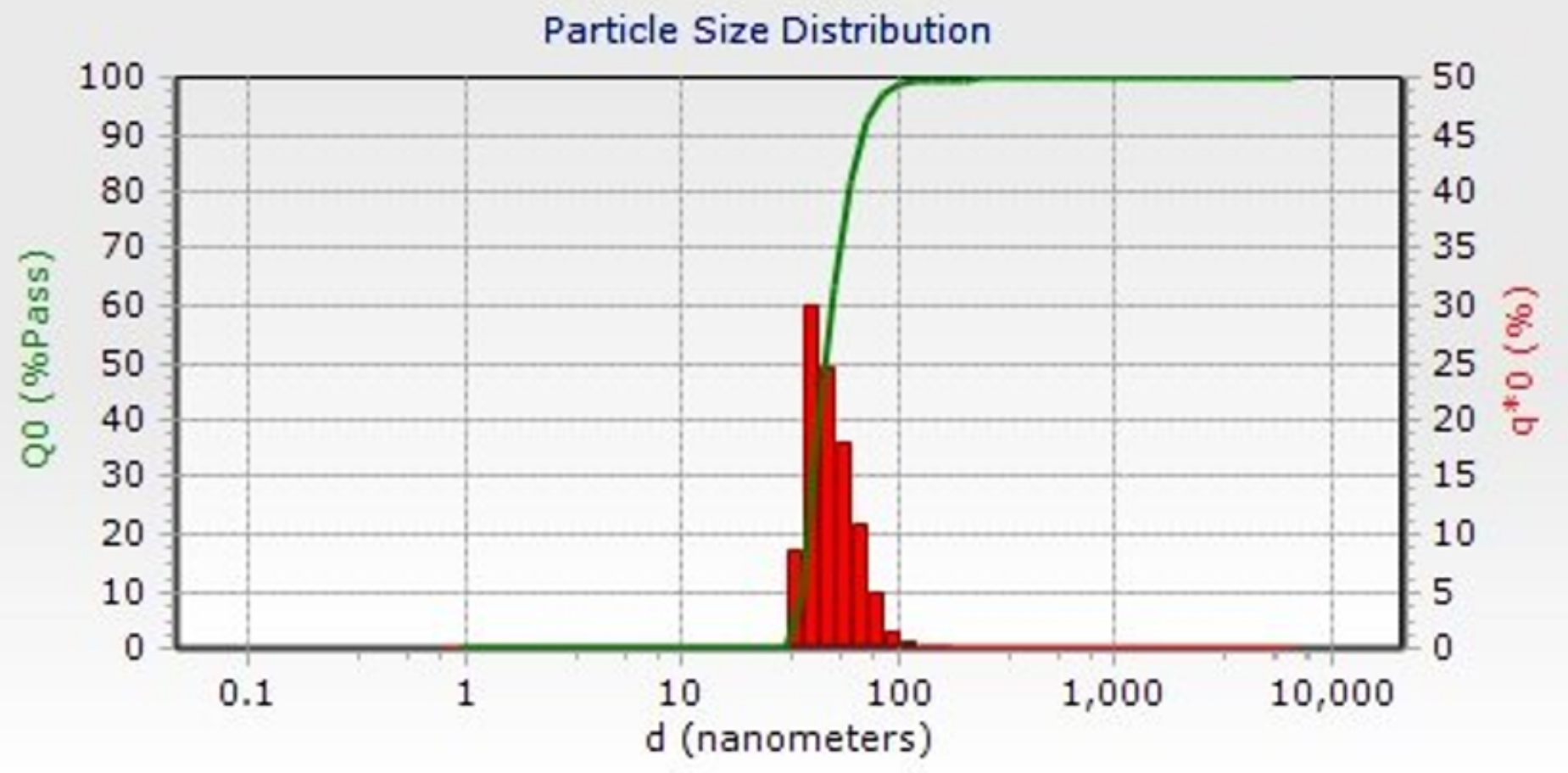

Figure 3

Size distribution of ZnO NPs with maximum intensity at $46.3 \mathrm{~nm}$. 
Spectrum

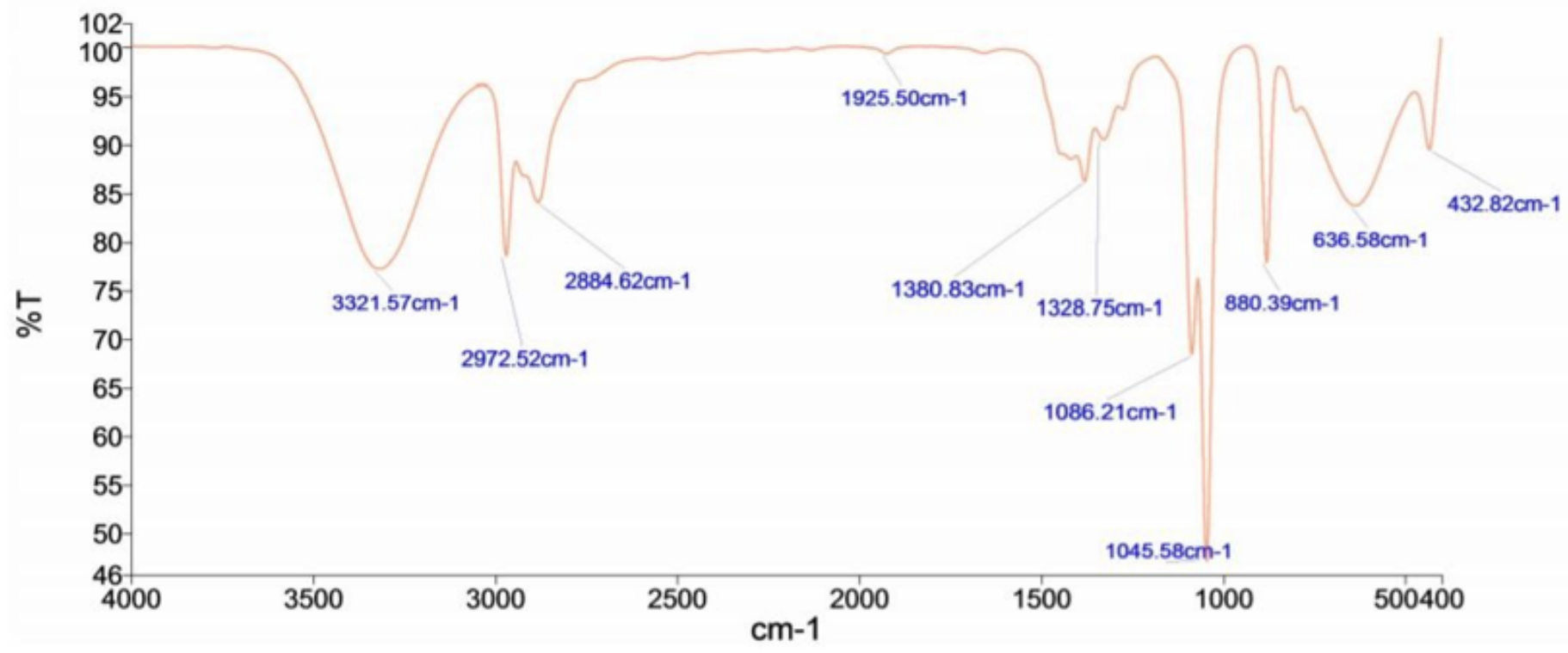

A.

\section{Spectrum}

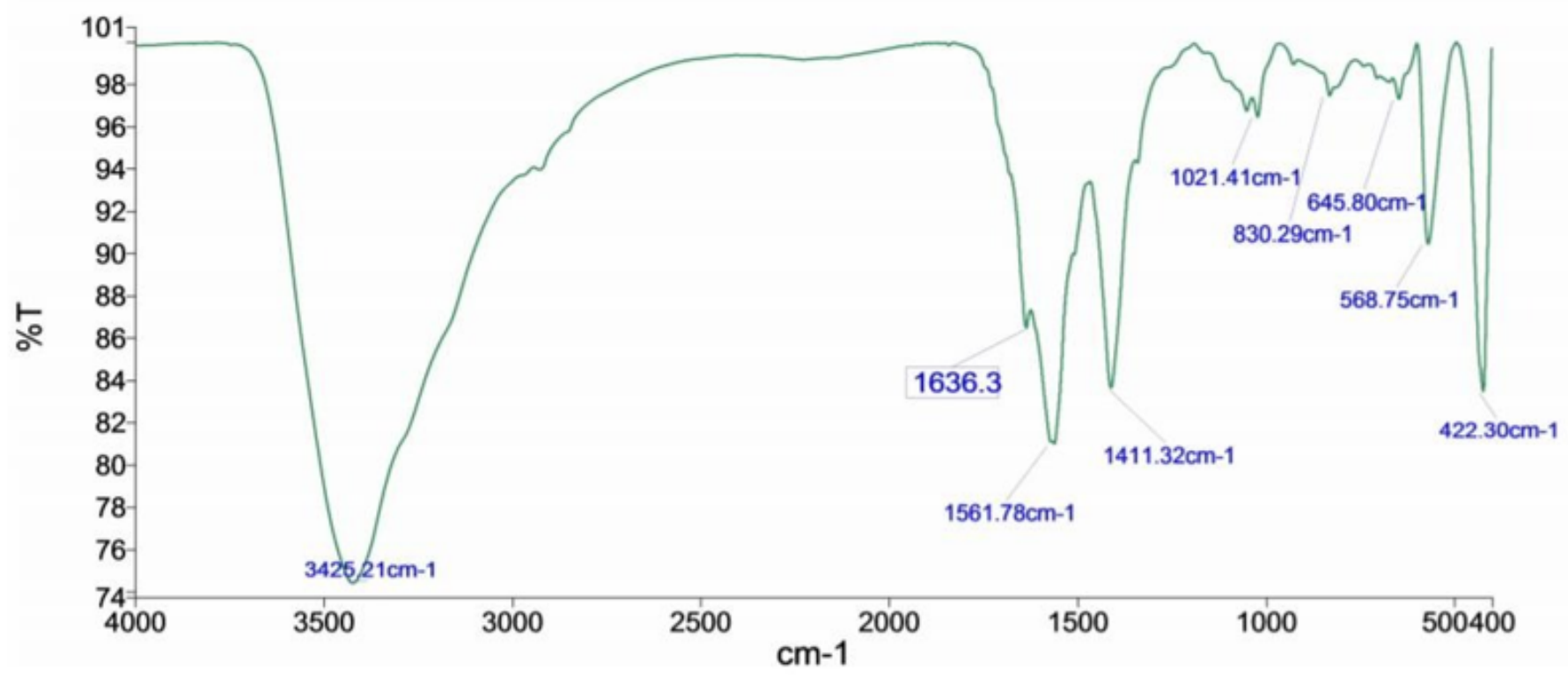

B.

Figure 4

FTIR Spectrum of ZnO NPs (A) Plant extract (B) ZnO NPs 


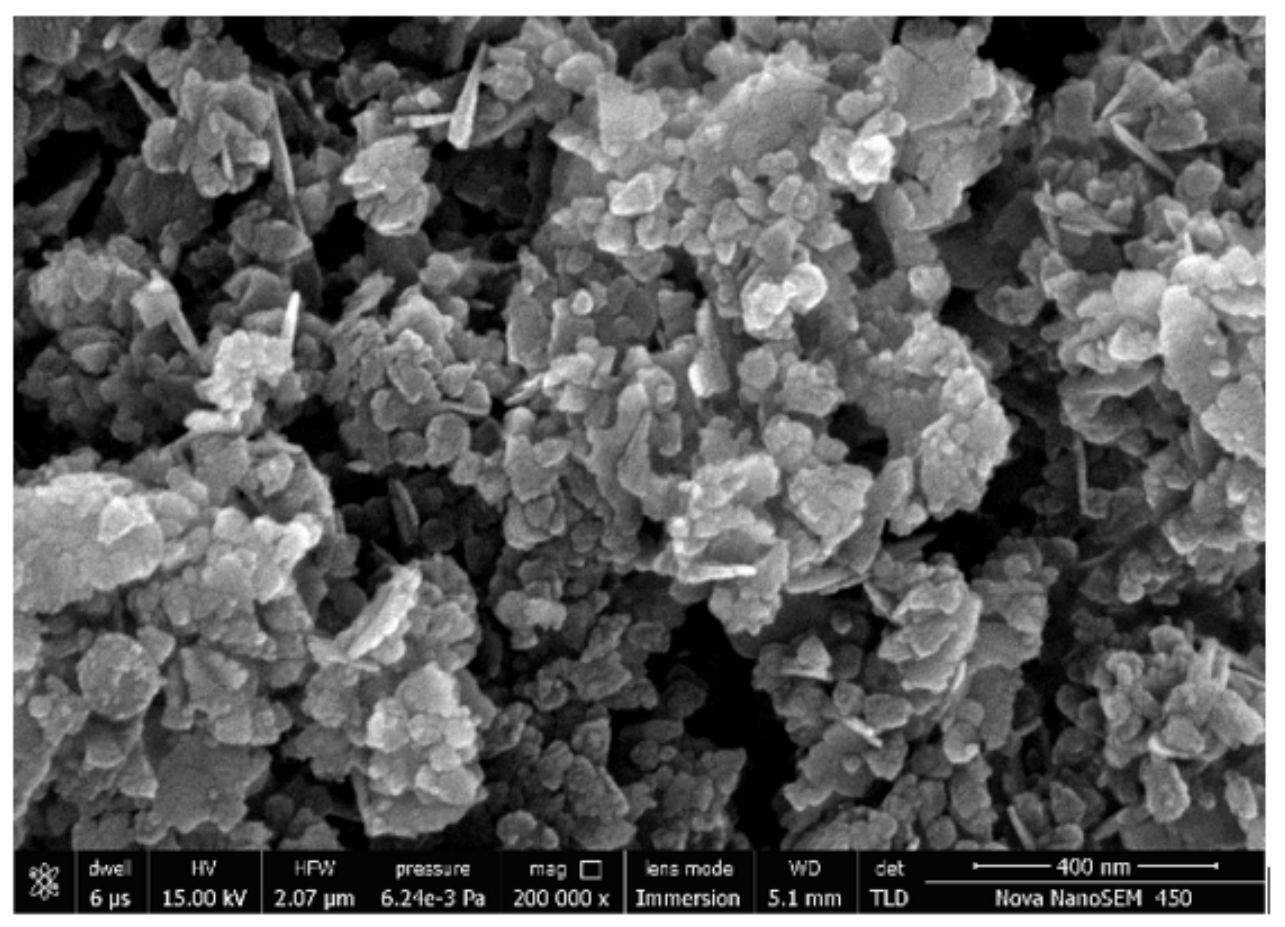

\section{(A)}

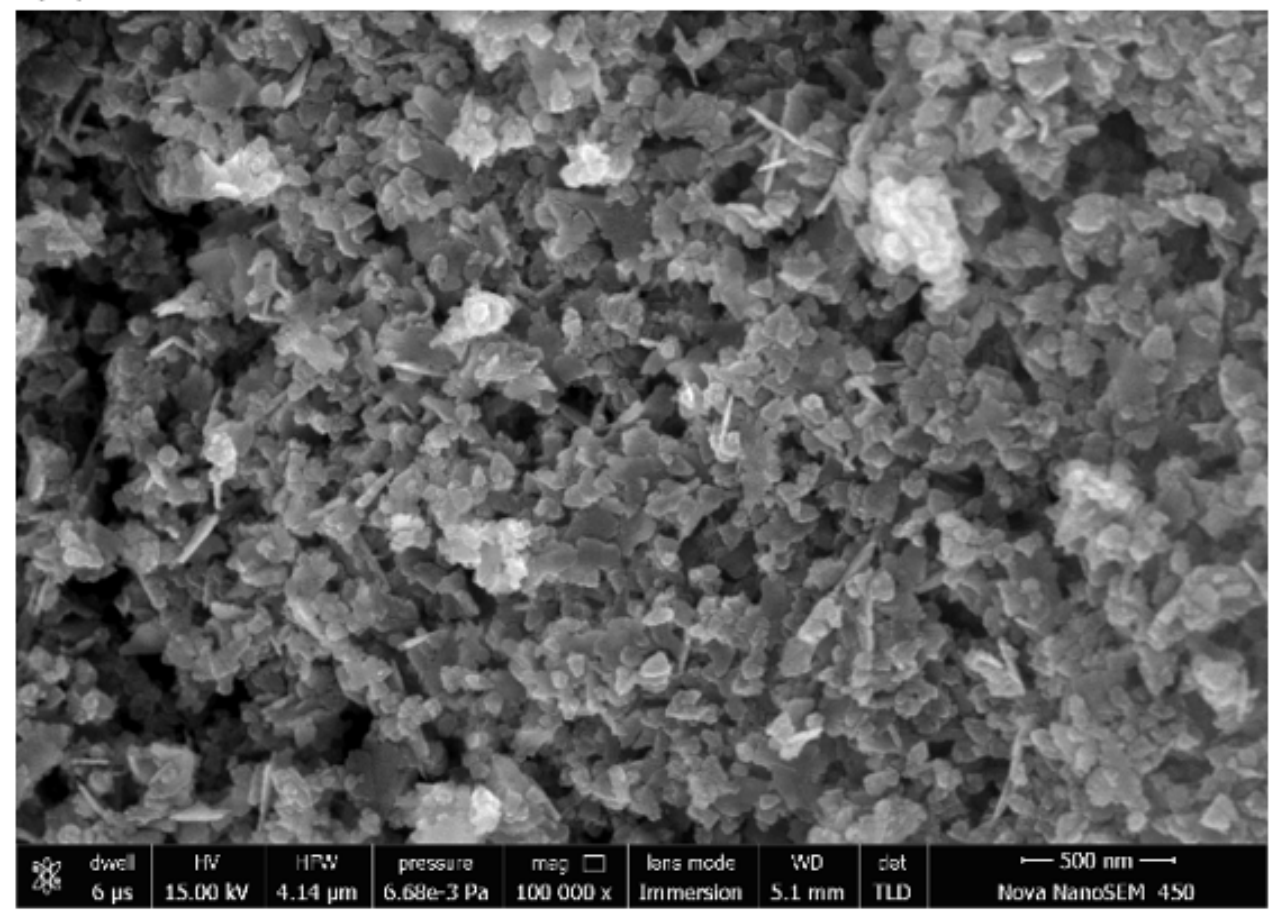

(B)

\section{Figure 5}

FE-SEM Images of ZnO NPs in different magnification ranges (A) 400nm (B) $500 \mathrm{~nm}$ FE-SEM of ZnO NPs in different magnification ranges. 


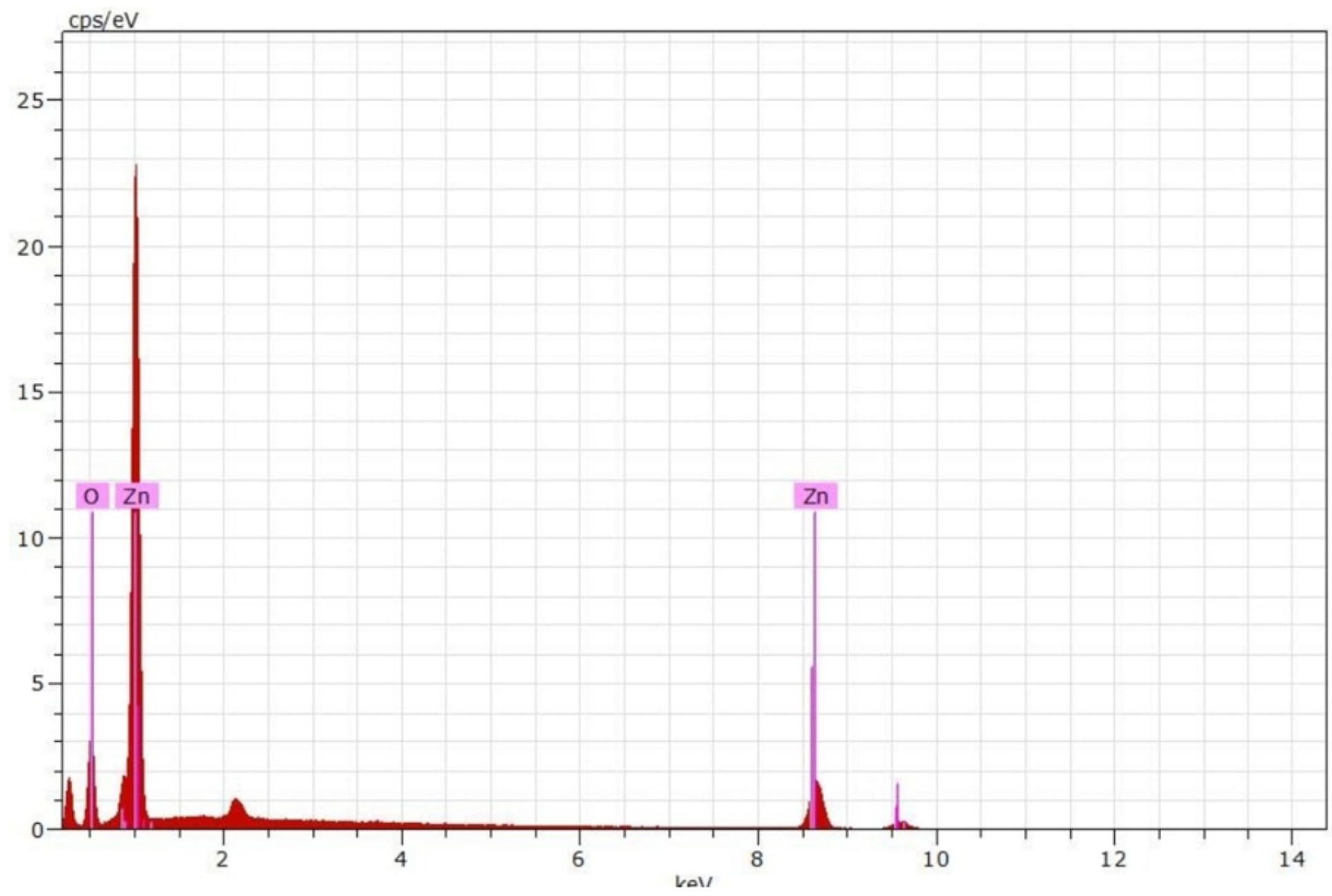

Figure 6

EDS Spectrum of ZnO NPs.

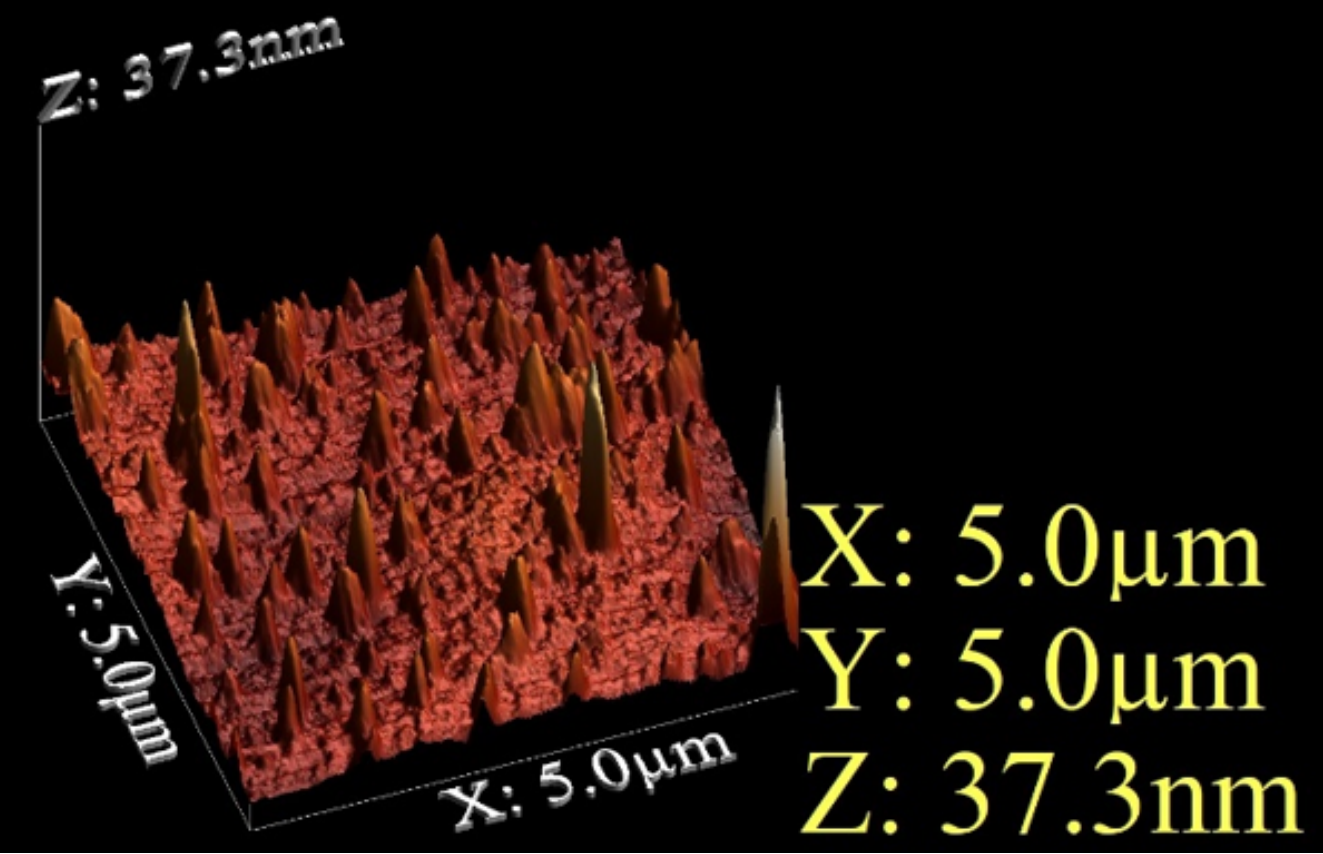


Figure 7

AFM of ZnO NPs synthesized by plant extract.

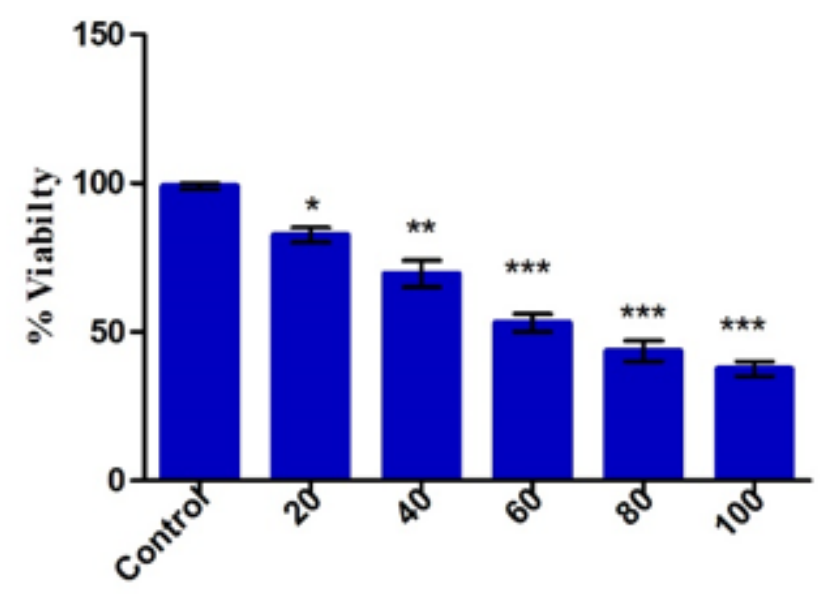

(A)

Concentration $(\mu \mathrm{g} / \mathrm{ml})$

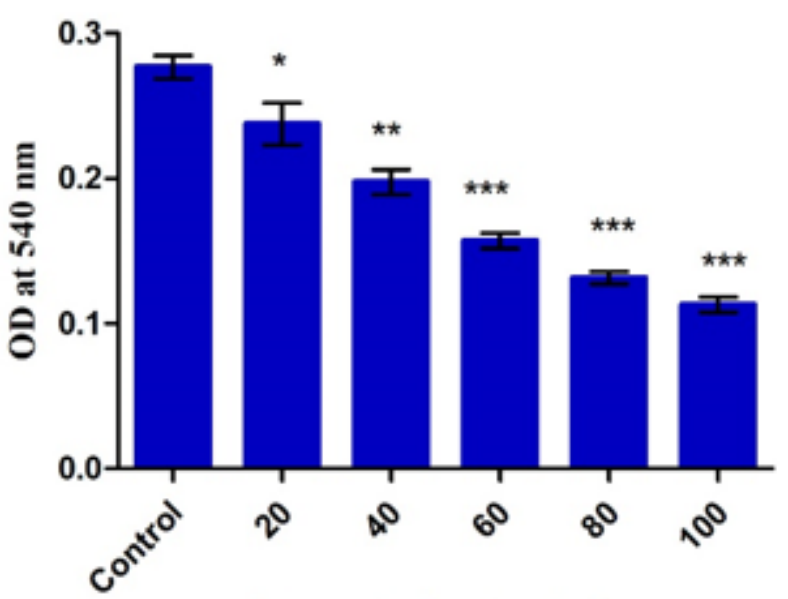

(B)

Concentration $(\mu \mathrm{g} / \mathrm{ml})$

Figure 8

Cytotoxicity analysis of ZnO NPs on human colon cancer line (SW-480) (A) MTT assay (B) NRU assay activity. 